\title{
Impact of various issues on extending the useful life of a product through product recovery options
}

\author{
Kampan Mukherjee ${ }^{1} \cdot$ Sandeep Mondal $^{2}$ • \\ Kaustov Chakraborty ${ }^{2}$
}

Received: 15 March 2017 / Accepted: 27 April 2017 / Published online: 10 July 2017

(C) Springer Science+Business Media Dordrecht 2017

\begin{abstract}
Due to the growing consciousness towards environment and stringent governmental legislations, manufacturers are incorporating product recovery activities in their business processes. In product recovery process, used products are collected after their end-of-use from the customers and their retained usable values are recovered through value additive operations. The product recovery options not only reduce the disposal of wastes but also extend the useful life of product. In this paper, we try to identify various issues from literature review, which influence the extension of useful life of products through product recovery options. These issues are further classified into five major decision areas namely product design issues, operational issues, market related issues, governmental rules and legislations, and societal issues. The contextual relationships among these set of issues are studied by using Fuzzy Interpretive Structural Modelling (FISM), which reflects different levels of influence. Two case studies are highlighted here to compare the contextual relationships among these decision-making issues. The issues in the highest-level act as the prime enablers which trigger the extension of product life and help in formation of corporate strategies. The issues in the lower level generally act as operational issues.
\end{abstract}

Keywords Product life cycle · Product recovery options · Fuzzy Interpretive structural modelling

\section{Introduction}

Any product undergoes several phases in its product life cycle. These phases are extraction of raw material, production of finished product, its use and after its use finally disposal. We can also describe the product life cycle as the total sales turnover of the product over a time period.

Kampan Mukherjee

Kampan.mukherjee@iimkashipur.ac.in

1 Indian Institute of Management, Kashipur, India

2 Indian Institute of Technology (Indian School of Mines), Dhanbad, India 
Useful life of the product is the duration of time period in which the items remain useful to the customer. End user environments, frequency of use are some factors which affect the useful life of the product. After its useful life, the product is usually disposed to the environment resulting in pollution, landfill or incineration. So, there is the necessity of evolving some activities which can control pollution, avoid land filling or incineration and preserve the natural resources. One such approach is product recovery operation. By the product recovery operation, we can retrieve the retained used value from the used product. Different product recovery options are repair, reuse, refurbishment, remanufacturing, cannibalization and recycling. Using these aforesaid options, we can extend the useful life of the product, shown in Fig. 1. The aim of the useful life extension of the product is to reduce the environmental impact in long run, while increasing the societal and economic value of the product.

The first step of the product recovery operation is to collect the used products from the end users. The used products are then sorted, disassembled, repaired or remanufactured, reassembled and sold in the market. From the literature review, we have identified different issues which have significant impact in useful life extension of a product. These issues are clustered into five main groups such as Design of product, Operational issue, Market of remanufactured product, Government legislation and Environmental Consciousness, shown in Table 1. The objective of the paper is to study the contextual relationships among the identified issues in Table 1. Interpretive Structural Modelling (ISM) along with type -1 Fuzzy set theory is used to draw the contextual relationships. Two case examples are considered in this paper to illustrate the Fuzzy Interpretive Structural Modelling (FISM) methodology.

The rest of the paper is organized as follows. In "Fuzzy interpretive structural modelling (FISM)"section we discussed on Fuzzy Interpretive structural modelling (FISM). In "Illustration with an example" section we used FISM methodology to find the structural relationship between the identified issues for extension of useful life of the product, which is followed by discussion and conclusion in fourth and fifth section respectively.

\section{Fuzzy interpretive structural modelling (FISM)}

Multi Criteria Decision Making (MCDM) is classified into two categories, Classical MCDM method and Fuzzy MCDM method [27]. In classical MCDM methods individual preferences are usually represented by numbers, expressing exact degree of preferences of decision makers. On the other hand, in Fuzzy MCDM individual preferences are expressed by linguistic

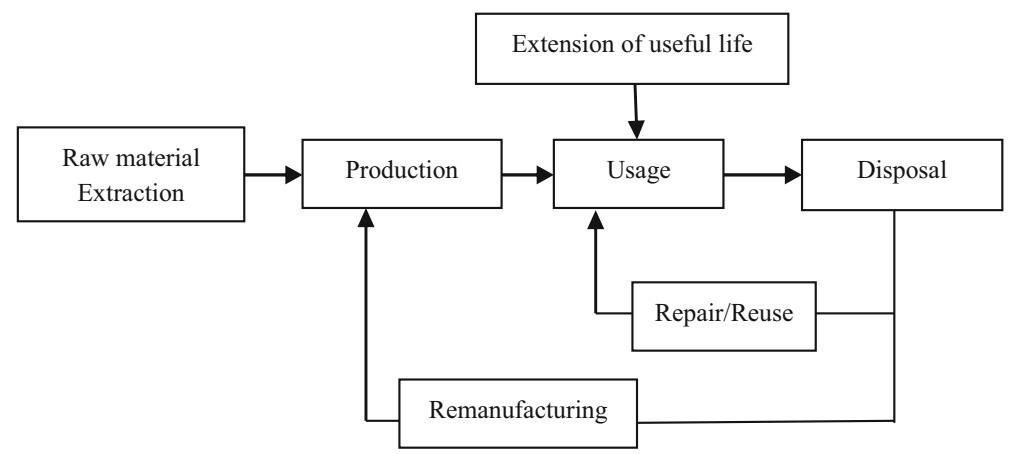

Fig. 1 Product life cycle and extension of useful life (Adopted from Kobayashi H. [1]) 
Table 1 Issues identified from the literature review

\begin{tabular}{|c|c|c|}
\hline Issues & Sub Issues & References \\
\hline 1. Operational & $\begin{array}{l}\text { Collection process, disassembly, } \\
\text { reconditioning, reassembly, inventory, } \\
\text { production planning \& control }\end{array}$ & $\begin{array}{l}\text { Mondal and Mukherjee [2], Galberth and } \\
\text { Blackburn [3], Teunter et al. [4], } \\
\text { Wassenhove et al. [5], Guide et al. [6], } \\
\text { Fergunson et al. [7]; Fleischmann et al. } \\
\text { [8]; El. Saadany [9]; Fleischmann et al. } \\
\text { [10] }\end{array}$ \\
\hline 2. Product design & $\begin{array}{l}\text { Design of fasteners, modular design, design } \\
\text { for cleaning (DfC), Design for inspection } \\
\text { (DfI), part complexity, minimization of } \\
\text { number of parts }\end{array}$ & $\begin{array}{l}\text { Shu and Flowers [11], Ijomah et al. [12], Go } \\
\text { et al. [13]; Zwolinski et al. [14], Kimura } \\
\text { et al. [15], Brennan et al. [16], Desai and } \\
\text { Mittal [17] }\end{array}$ \\
\hline $\begin{array}{l}\text { 3. Market of } \\
\text { remanufactured } \\
\text { product }\end{array}$ & $\begin{array}{l}\text { Identification of market, attitude of the } \\
\text { customers, selling price of } \\
\text { remanufactured product. }\end{array}$ & $\begin{array}{l}\text { Subramaniom et al. [18]; Atasu et al. [19], } \\
\text { Parra et al. [20], Ostlin et al. [21], Rathore } \\
\text { et al. [22] }\end{array}$ \\
\hline $\begin{array}{l}\text { 4. Governmental } \\
\text { Laws \& } \\
\text { Legislations }\end{array}$ & & Johnson et al. [23]; Xiang and Miang [24] \\
\hline $\begin{array}{r}\text { 5.Environmental } \\
\text { consciousness }\end{array}$ & & Gungor and Gupta [25], Ilgin and Gupta [26] \\
\hline
\end{tabular}

terms to indicate the hesitation or imprecision related to the preferences. Interpretive Structural Modelling or ISM (developed by Warfield, 1973 [28]) is a well-known classical structural MCDM method. ISM depicts structural relationships between the issues or factors in the system. The input data for modelling the relationships are obtained from experts. Many researchers [29-31] have used ISM methodology in different situations like reverse logistics, remanufacturing, offshore alliances etc.

In this paper, we incorporate the fuzzy logic in the ISM model for structuring the relations among various issues of remanufacturing business. The hesitation and ambiguity during elicitation of expert's opinion is captured by fuzzy data. In fuzzy logic, we convert the crisp set into fuzzy set using the membership functions, which is followed by defuzzification of fuzzy data into crisp data. The steps in Fuzzy ISM (FISM) are discussed below.

Step 1: The first step is identification of the issues and sub issues in the system.

Step 2: The Structural Self-Interaction Matrix (SSIM) is developed from the opinions by the experts. In FISM, linguistic terms are used to describe the ambiguity in the experts' inputs, which represent the membership function. Here we use triangular fuzzy membership function (shown in Fig. 2) considering the linguistic terms as shown in Table 2.

Experts use the following notation: $\mathrm{V}, \mathrm{A}, \mathrm{X}, \mathrm{O}$ to represent the influences between issues. $\mathrm{V}$ represents that issue $\mathrm{i}$ influences issue $\mathrm{j}$ but the opposite is not true. $\mathrm{V}(\mathrm{VH}), \mathrm{V}(\mathrm{H}), \mathrm{V}(\mathrm{L})$ and $\mathrm{V}(\mathrm{VL})$ are the linguistic representations of degree of influence. A represents that issue $\mathrm{j}$ influences issue $\mathrm{i}$ but the opposite is not true. Similarly, the linguistic representations are A (VH), A (H), A (L) and A (VL). X represents that both the issues $\mathrm{i}$ and $\mathrm{j}$ influence each other. The bidirectional relationships may be represented in two ways for two different situations. If the degree of influence in both the directions is same, it is represented as X (.), whereas, if it is different, it is shown as $\mathrm{X}(.,$.$) . In both the cases the four possible linguistic terms may be used.$ For example, $\mathrm{X}(\mathrm{VH})$ stands for the case, when the influence of issue $\mathrm{i}$ on $\mathrm{j}$ and also the 


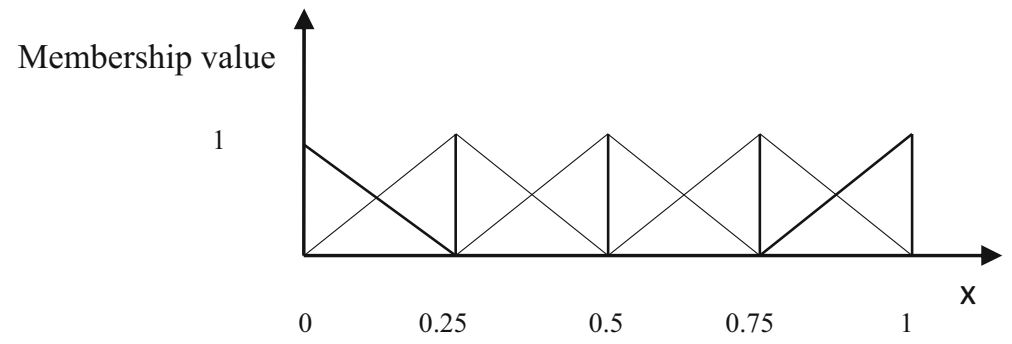

Fig. 2 Triangular membership function (Adopted from Khatwani et al. [27])

influence of issue $\mathrm{j}$ on $\mathrm{i}$ are same and Very High (VH). On the other hand, $\mathrm{X}(\mathrm{VH}, \mathrm{H})$ represents the situation, when the influence of issue $i$ on issue $j$ is Very High (VH), but the influence of issue $\mathrm{j}$ on $\mathrm{i}$ is High $(\mathrm{H})$. The last one is $\mathrm{O}$ which represents that issue $\mathrm{i}$ and $\mathrm{j}$ have no influence on each other and the linguistic term is represented by $\mathrm{O}$ (No).

Step 3: Aggregated SSIM is formed by the choice of experts with the maximum frequencies. Subsequently Final Fuzzy Reachability Matrix is developed by using values in place of linguistic terms as shown in Table 2.

As an example of bi-directional influences, expert's expression of $\mathrm{X}(\mathrm{VH}, \mathrm{L})$ is replaced by $(0.75,1,1)$ in $(i, j)$ direction and by $(0.25,0.5,0.75)$ in $(j, i)$ direction.

For $\mathrm{O}(\mathrm{No})$, both $(\mathrm{i}, \mathrm{j})$ and $(\mathrm{j}, \mathrm{i})$ will be replaced by $(0,0,0.25)$.

Step 4: Driving power and dependence power are calculated by summing up the rows and columns respectively from the Final Fuzzy Reachability Matrix. The fuzzy operations shown in eq. (1) are carried out to calculate the dependence and driving power.

$$
\begin{gathered}
A_{1}=\left(a_{1}, b_{1}, c_{1}\right) \text { and } A_{2}=\left(a_{2}, b_{2}, c_{2}\right) \\
A_{1} \oplus A_{2}=\left(a_{1}+a_{2}, b_{1}+b_{2}, c_{1}+c_{2}\right)
\end{gathered}
$$

For the MICMAC analysis (classification of issues under four segments) we have to defuzzify the driving and dependence power of the Final Fuzzy Reachability Matrix. The defuzzification process [27] is done by applying the eqs. 2, 3, 4 and 5.

Let $A_{k}=\left(a_{k}, b_{k}, c_{k}\right) \quad$ where $k=1,2, \ldots, n$

Compute the minimum value of $a_{k}, k=1,2, \ldots n$ and the maximum value of $c_{k}, k=1$, $2, \ldots . . n$ and then calculate the difference between them.

Table 2 Linguistic terms (Adopted from Khatwani et al. [27])

\begin{tabular}{cc}
\hline Linguistic terms & Values \\
\hline No impact(No) & $(0,0,0.25)$ \\
Very low impact(VL) & $(0,0.25,0.5)$ \\
Low impact (L) & $(0.25,0.5,0.75)$ \\
High impact (H) & $(0.5,0.75,1)$ \\
Very impact (VH) & $(0.75,1,1)$ \\
\hline
\end{tabular}




$$
X=\min \left(a_{k}\right), Y=\max \left(c_{k}\right) \text { then } D=(Y-X)
$$

Subsequently,

$$
p_{a k}=\frac{a_{k}-X}{D}, p_{b k}=\frac{b_{k}-X}{D}, p_{c k}=\frac{c_{k}-X}{D}
$$

The normalized values are computed by the eq. (3)

$$
p_{k}^{l s}=\frac{p_{b k}}{1+p_{b k}-p_{a k}} \quad \text { and } \quad p_{k}^{r s}=\frac{p_{c k}}{1+p_{c k}-p_{b k}}
$$

After getting the normalized values, we have to calculate the normalized crisp (defuzzified) value based on the following eq. (4).

$$
p_{k}^{c r i s p}=\frac{\left[p_{k}^{l s}{ }^{*}\left(1-p_{k}^{l s}\right)+p_{k}^{r s} p_{k}^{r s}\right]}{1-p_{k}^{l s}+p_{k}^{r s}}
$$

Finally, it is the calculation of the crisp value for $A_{k}$ by eq. (5)

$$
A_{k}^{\text {crisp }}=X+p_{k}^{\text {crisp }}{ }^{*} D
$$

Step 5: Defuzzified reachability matrix undergoes level partitioning operation by replacing the linguistic term VH, $\mathrm{H}$ by 1 and L, VL, No by 0 in the Aggregated SSIM matrix. The transitivity is checked before partitioning of the defuzzified reachability matrix to levels. For the level partition, we need to calculate the reachability set and antecedent set. Reachability set of an issue is calculated along the row of the corresponding issue where the value is 1 and the antecedent set of an issue is calculated along the column where the value is 1 . An intersection set is developed by the common elements between the reachability and antecedent set. The issues having the same reachability and intersection set are leveled as 1 and are eliminated from the remaining issues. Same process is continued until all the issues get leveled.

Step 6: The last step is to draw the FISM digraph.

\section{Illustration with an example}

A case study is used to illustrate the aforesaid methodology of FISM. In this case study, we try to compare the various decision-making issues related to the product recovery management process between two original equipment manufacturers. The first original equipment manufacturer is an Indian company (OEM 1) who remanufacturers their own manufactured printer cartridge whereas, the second original equipment manufacturer is a multinational company (OEM 2) who remanufacturers their own alternators. The remanufacturing facility of OEM 1 is situated in the eastern part of India and the remanufacturing facility of OEM 2 is in the central part of India. Both the OEM collects their own product from the customers and then process according to the stages of remanufacturing and finally sell the remanufactured product in the market. However, the weightages of the decision-making issues are not same for OEM 1 and OEM 2.

Step 1: Responses from 5 experts have been collected to develop the relationships among the identified issues and sub-issues. Out of five experts, three are from the industries and 
Table 3 Aggregated SSIM matrix related to the five main issues for OEM 1 and OEM 2

\begin{tabular}{|c|c|c|c|c|c|}
\hline Main Issues for OEM 1 & I1 & $\mathrm{I} 2$ & $\mathrm{I} 3$ & I4 & I5 \\
\hline Product design (I1) & & $\mathrm{V}(\mathrm{VH})$ & $\mathrm{V}(\mathrm{H})$ & $\mathrm{A}(\mathrm{L})$ & $\mathrm{A}(\mathrm{VH})$ \\
\hline Operational (I2) & & & $\mathrm{O}(\mathrm{No})$ & $\mathrm{A}(\mathrm{H})$ & $\mathrm{A}(\mathrm{L})$ \\
\hline Market of remanufactured product (I3) & & & & $\mathrm{A}(\mathrm{H})$ & $\mathrm{X}(\mathrm{L}, \mathrm{H})$ \\
\hline Governmental Laws \& Legislations (I4) & & & & & $\mathrm{A}(\mathrm{VH})$ \\
\hline \multicolumn{6}{|l|}{ Environmental consciousness (I5) } \\
\hline Main issues for OEM 2 & I1 & $\mathrm{I} 2$ & $\mathrm{I} 3$ & $\mathrm{I} 4$ & I5 \\
\hline Product dDesign (I1) & & $\mathrm{V}(\mathrm{VH})$ & $\mathrm{V}(\mathrm{H})$ & $\mathrm{A}(\mathrm{L})$ & $\mathrm{A}(\mathrm{VH})$ \\
\hline Operational (I2) & & & $\mathrm{O}(\mathrm{No})$ & $\mathrm{A}(\mathrm{H})$ & $\mathrm{A}(\mathrm{H})$ \\
\hline Market of remanufactured product (I3) & & & & $\mathrm{A}(\mathrm{H})$ & $\mathrm{X}(\mathrm{H}, \mathrm{H})$ \\
\hline Governmental Laws \& Legislations (I4) & & & & & $\mathrm{X}(\mathrm{H}, \mathrm{H})$ \\
\hline Environmental consciousness (I5) & & & & & \\
\hline
\end{tabular}

remaining two are from academics. Experts from the industries are different in case of studying the contextual relationships for OEM 1 and OEM 2. For OEM 1, we consider the experts from OEM 1 and for OEM 2, we consider experts from OEM 2. For this analysis, we consider only top management as experts. All the experts have experienced more than ten years in their respective fields.

Step 2: Self Structural Interaction Matrices (SSIM) are developed based on the opinion of each expert. The all five SSIM of the main issues are shown in Table 12 in Appendix A, as an example. Then Aggregated SSIM matrices for OEM 1 and OEM 2 are prepared based on the opinion (in linguistic term) occurring maximally among 5 experts and these are shown in Tables 3, 4, 5 and 6.

Step 3: The Aggregated SSIM matrix is transformed into the Final Fuzzy Reachability Matrix by replacing value of the linguistic terms according to Table 2. The Final Fuzzy Reachability Matrix of the main issues is shown in Table 1. The remaining Final Fuzzy Reachability Matrix related to operational issue, product design and marketing issue are shown in Tables 13, 14 and 15 in Appendix A respectively.

Step 4: The driving power and dependence power are obtained from the Final Fuzzy Reachability Matrix of OEM 1 and OEM 2 as per eq. (1). For MICMAC analysis, we have defuzzified the dependence and driving power values by using the eqs. 2, 3, 4 and 5 and have obtained the crisp values as shown in Tables 7.

Table 4 Aggregated SSIM matrix related to the Operational Issues for OEM 1 and OEM 2

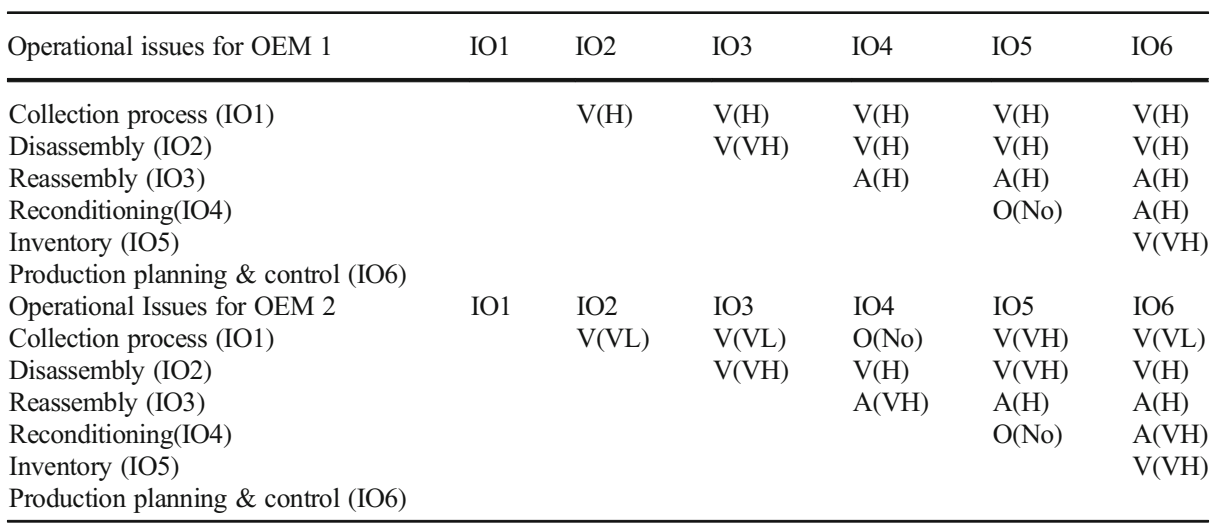


Table 5 Aggregated SSIM matrix related to the Design of the product for OEM 1 and OEM 2

\begin{tabular}{|c|c|c|c|c|c|c|}
\hline Product design issues for OEM 1 & ID1 & ID2 & ID3 & ID4 & ID5 & ID6 \\
\hline $\begin{array}{l}\text { Design of Fasteners (ID1) } \\
\text { Modular Design (ID2) } \\
\text { Avoid Complexity (ID3) } \\
\text { Minimize No. of Parts (ID4) } \\
\text { Design for Cleaning (ID5) } \\
\text { Design for Inspection (ID6) } \\
\text { Product design issues for OEM } 2 \\
\text { Design of Fasteners (ID1) } \\
\text { Modular Design (ID2) } \\
\text { Avoid Complexity (ID3) } \\
\text { Minimize No. of Parts (ID4) } \\
\text { DfC (ID5) } \\
\text { DfI (ID6) }\end{array}$ & ID1 & $\begin{array}{c}\text { ID2 } \\
\text { V(H) }\end{array}$ & $\begin{array}{c}\text { ID3 } \\
\text { V(L) } \\
\text { V(H) }\end{array}$ & $\begin{array}{l}\text { ID4 } \\
\mathrm{X}(\mathrm{H}) \\
\mathrm{V}(\mathrm{H}) \\
\mathrm{X}(\mathrm{H})\end{array}$ & $\begin{array}{l}\text { ID5 } \\
\text { V(H) } \\
\text { X (H, L) } \\
\text { V (VH) } \\
\text { V(VH) }\end{array}$ & $\begin{array}{l}\text { X(H) } \\
\text { X(H) } \\
\text { V(VH) } \\
\text { V(VH) } \\
\text { X(VH) } \\
\text { ID6 } \\
\text { V(H) } \\
X(H, L) \\
\text { V (VH) } \\
\text { V(VH) } \\
\text { X(L) }\end{array}$ \\
\hline
\end{tabular}

From Table 7, for OEM 1 , the fuzzy value of the driving power of I1 is $\left(a_{1}, b_{1}, c_{1}\right)=(2.25$, 2.75,3.5), we find the value of $X=\min \left(a_{k}\right)=1$ and $Y=\max \left(c_{k}\right)=4.75$ from the driving power column, so $D=(Y-X)=3.75$. Then, $p_{a 1}=0.33, p_{b 1}=0.466, p_{c 1}=0.666, p_{1}^{l s}=$ 0.410 and $p_{1}^{r S}=0.555$

$$
p_{1}^{\text {crisp }}=0.480 \text { and } A_{1}^{\text {crisp }}=2.8
$$

Dependence power of I1 is $\left(a_{1}, b_{1}, c_{1}\right)=(2,2.5,3.25)$ and $X=\min \left(a_{k}\right)=1.25, Y=$ $\max \left(c_{k}\right)=4.25$ and $D=(Y-X)$. Then, $p_{a 1}=0.25, p_{b 1}=0.416, p_{c 1}=$ $0.666, p_{1}^{l s}=0.356$ and $p_{1}^{r s}=0.532$

$$
p_{1}^{\text {crisp }}=0.054 \text { and } A_{1}^{\text {crisp }}=1.412
$$

Similarly, for OEM 2, in Table 7 , the driving power of I4 is $\left(a_{1}, b_{1}, c_{1}\right)=$ $(2.75,3.75,4.75)$, then the crisp value of I4 is 3.7 and the crisp value of the fuzzy dependence value of I4 is 1.91 .

The driving and dependence power calculation for the remaining issues for OEM 1 and OEM 2 are shown in Appendix A. The outcome of MICMAC analysis for OEM 1 and OEM 2 is shown in Figs. 3 and 4 respectively

Step 5: The defuzzified reachability matrix is formed by replacing the value of $\mathrm{VH}, \mathrm{H}$ by 1 and L, VL, No by 0 of the Aggregated SSIM matrix and the level partitioning operation for OEM 1 and OEM 2 is shown in Tables 8, 9, 10 and 11.

\begin{tabular}{|c|c|c|c|}
\hline Market related issues for both OEM 1 and OEM 2 & Irm1 & Irm2 & Irm3 \\
\hline $\begin{array}{l}\text { Identification of Market ( } \operatorname{Irm} 1 \text { ) } \\
\text { Attitude of the Customer (Irm2) } \\
\text { Selling price of remanufactured product (Irm3) }\end{array}$ & & $\mathrm{A}(\mathrm{VH})$ & $\begin{array}{l}\mathrm{A}(\mathrm{VH}) \\
\mathrm{A}(\mathrm{L})\end{array}$ \\
\hline
\end{tabular}

Table 6 Aggregated SSIM matrix related to the market of remanufactured product for OEM 1and OEM 2 


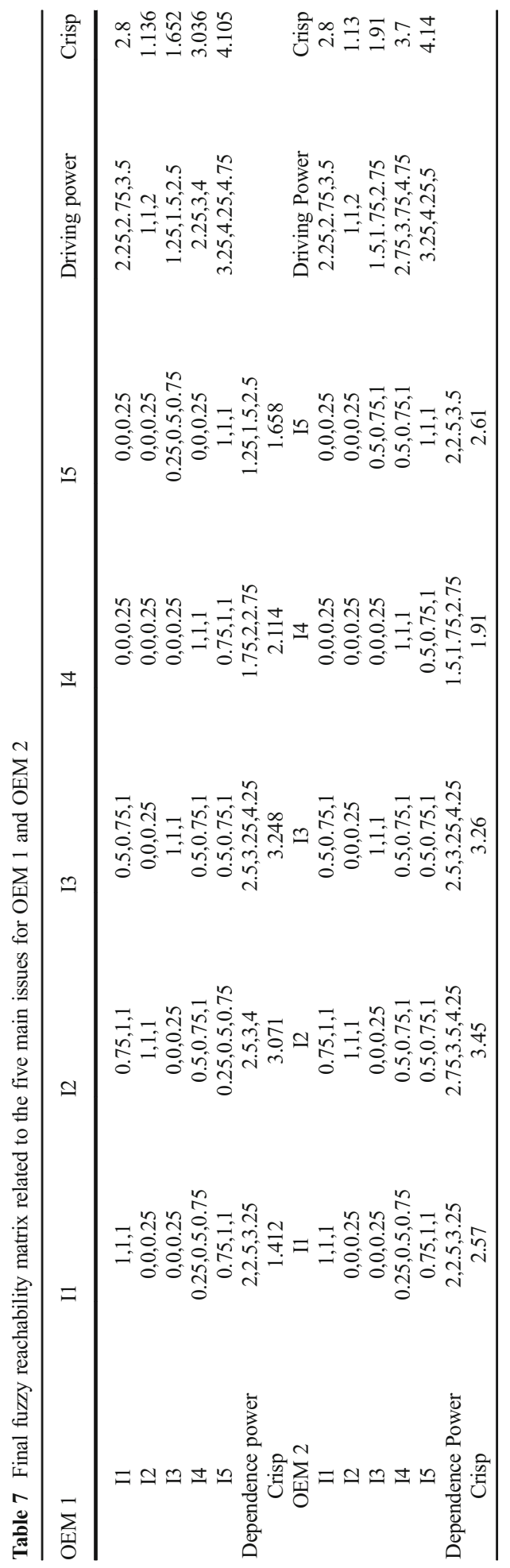




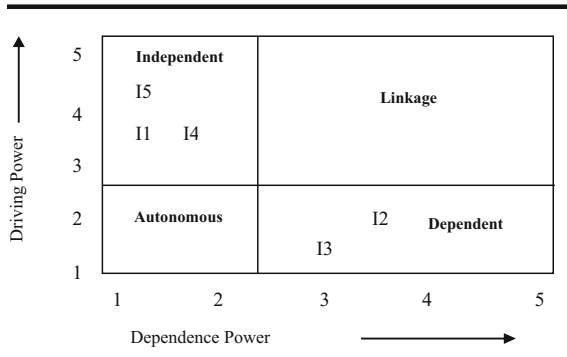

(a) MICMAC analysis of the five main issues

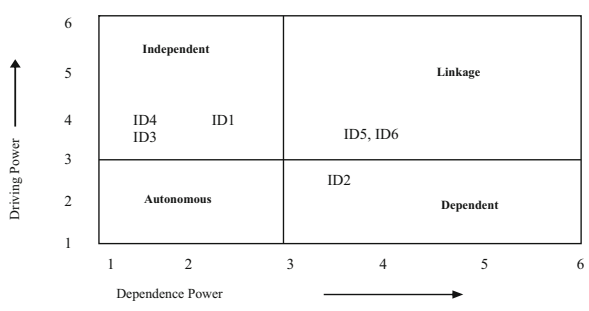

(c) MICMAC analysis related to the Design of the product

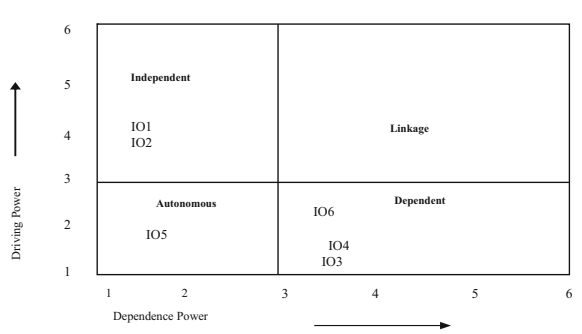

(b) MICMAC analysis related to the Operational

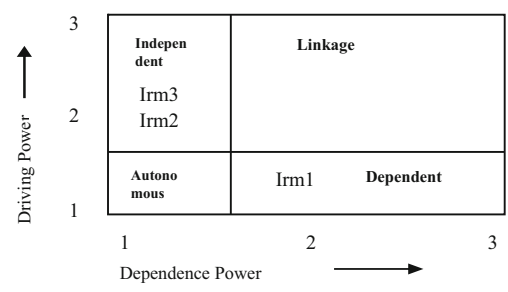

(d) MICMAC analysis related to the market

Fig. 3 MICMAC analysis among the main issues, operational issue, design and marketing issue for OEM 1

Step 6: The defuzzified FISM digraph for OEM 1 and OEM 2 is shown in Figs. 5 and 6. Figures 7 and 8 represents the comprehensive FISM digraph by considering the above four figures for OEM 1 and OEM 2.

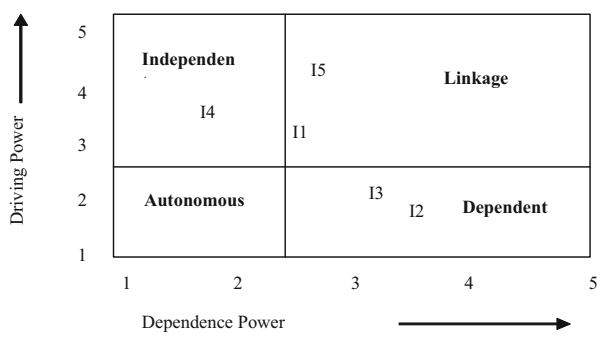

(a) MICMAC analysis of the five main issues

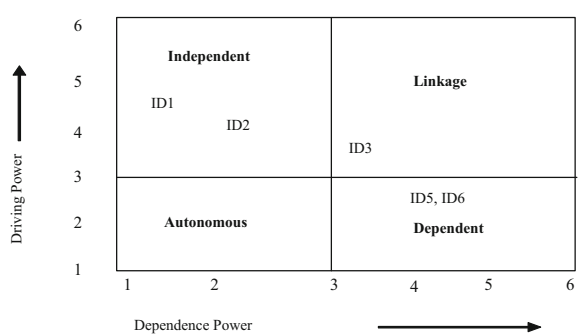

(c) MICMAC analysis related to the Design of the product

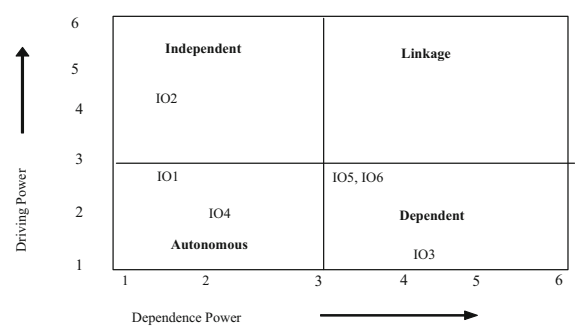

(b) MICMAC analysis related to the Operational

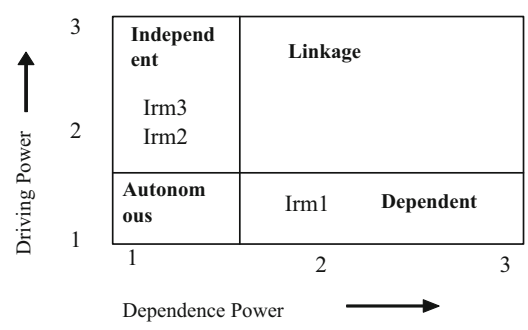

(d) MICMAC analysis related to the market

Fig. 4 MICMAC analysis among the main issues, operational issue, design and marketing issue for OEM 2 
Table 8 Level partitioning among the main issues for OEM 1 and OEM 2

\begin{tabular}{|c|c|c|c|c|}
\hline Main issues (OEM 1) & Reachability set & Antecedent set & Intersection set & Level \\
\hline I1 & $1,2,3$ & 1,5 & 1 & 2 \\
\hline $\mathrm{I} 2$ & 2 & $1,2,4$ & 2 & 1 \\
\hline $\mathrm{I} 3$ & 3 & $1,3,4,5$ & 3 & 1 \\
\hline I4 & $2,3,4$ & 4,5 & 4 & 2 \\
\hline I5 & $1,3,4,5$ & 5 & 5 & 3 \\
\hline Main issues (OEM 2) & Reachability set & Antecedent set & Intersection set & Level \\
\hline I1 & $1,2,3,5$ & $1,3,4,5$ & $1,3,5$ & 2 \\
\hline $\mathrm{I} 2$ & 2 & $1,2,3,4,5$ & 2 & 1 \\
\hline $\mathrm{I} 3$ & $1,2,3,4,5$ & $1,3,4,5$ & $1,3,4,5$ & 2 \\
\hline I4 & $1,2,3,4,5$ & $3,4,5$ & $3,4,5$ & 3 \\
\hline I5 & $1,2,3,4,5$ & $1,3,4,5$ & $1,3,4,5$ & 2 \\
\hline
\end{tabular}

In the FISM model, the level 1 issue is placed at the top position in the digraph which signifies its dependence property and the last level issue is placed at the bottom position in the digraph which signifies the driving characteristics of the issue. The other remaining issues are placed in the digraph according to their level.

\section{Results and discussion}

The relationship among five main issues for extension of useful life of a product through product recovery management for OEM 1and OEM 2 is depicted by the diagraph shown in Figs. 5 and 6 respectively and the MICMAC analysis is shown in Figs. 3 and 4. In the MICMAC analysis (shown in Figs. 3 and 4), each sub figure is divided into four quadrants.

\section{Autonomous issue-}

In the Autonomous segment, issues have weak driving power and dependence power. Autonomous issues have no significant contribution in decision making. Thus, they are removed from the system. For OEM 1, in Fig. 3(b) i.e. related to the operational

Table 9 Level partitioning among the Operational issues for OEM 1 and OEM 2

\begin{tabular}{lllll}
\hline Operational issue (OEM 1) & Reachability set & Antecedent set & Intersection set & Level \\
\hline IO1 & $1,2,3,4,5,6$ & 1 & 1 & $\mathbf{6}$ \\
IO2 & $2,3,4,5,6$ & 1,2 & 2 & $\mathbf{5}$ \\
IO3 & 3 & $1,2,3,4,5,6$ & 3 & $\mathbf{1}$ \\
IO4 & 3,4 & $1,2,4,5,6$ & 4 & $\mathbf{2}$ \\
IO5 & $3,4,5,6$ & $1,5,2$ & 5 & $\mathbf{4}$ \\
IO6 & $3,4,6$ & $1,2,5,6$ & 6 & $\mathbf{3}$ \\
Operational issue (OEM 2) & Reachability set & Antecedent set & Intersection set & Level \\
IO1 & 1,5 & 1 & 1 & $\mathbf{6}$ \\
IO2 & $2,3,4,5,6$ & 2 & 2 & $\mathbf{5}$ \\
IO3 & 3 & $2,3,4,5,6$ & 3 & $\mathbf{1}$ \\
IO4 & 3,4 & $2,4,5,6$ & 4 & $\mathbf{2}$ \\
IO5 & $3,4,5,6$ & $1,2,5$ & 5 & 4 \\
IO6 & $3,4,6$ & $2,5,6$ & 6 & $\mathbf{3}$ \\
\hline
\end{tabular}


Table 10 Level Partitioning among the issues related to the design of the product for OEM 1 and OEM 2

\begin{tabular}{lllll}
\hline Design issue (OEM 1) & Reachability set & Antecedent set & Intersection set & Level \\
\hline ID1 & $1,2,5,6$ & $1,2,3,4,5,6$ & $1,2,5,6$ & $\mathbf{1}$ \\
ID2 & $1,2,5,6$ & $1,2,3,4,5,6$ & $1,2,5,6$ & $\mathbf{1}$ \\
ID3 & $1,2,3,5,6$ & 3 & 3 & $\mathbf{2}$ \\
ID4 & $1,2,4,5,6$ & 4 & 4 & $\mathbf{2}$ \\
ID5 & $1,2,5,6$ & $1,2,3,4,5,6$ & $1,2,5,6$ & $\mathbf{1}$ \\
ID6 & $1,2,5,6$ & $1,2,3,4,5,6$ & $1,2,5,6$ & $\mathbf{1}$ \\
Design issue (OEM 2) & Reachability set & Antecedent set & Intersection set & Level \\
ID1 & $1,2,3,4,5,6$ & $1,2,3,4$ & $1,2,3,4$ & $\mathbf{2}$ \\
ID2 & $1,2,4,5,6$ & $1,2,4$ & $1,2,4$ & $\mathbf{2}$ \\
ID3 & $1,3,4,5,6$ & $1,3,4$ & $1,3,4$ & $\mathbf{2}$ \\
ID4 & $1,2,3,4,5,6$ & $1,2,3,4$ & $1,2,3,4$ & $\mathbf{2}$ \\
ID5 & 5 & $1,2,3,4,5$ & 5 & $\mathbf{1}$ \\
ID6 & 6 & $1,2,3,4,6$ & 6 & $\mathbf{1}$ \\
\hline
\end{tabular}

issue, has only one autonomous variable. However, for OEM 2, in Fig. 4 (b), has two autonomous variables. These factors are removed from the final FISM model.

\section{Dependent issue-}

In the Dependent segment, issues have strong dependent power and weak driving power. These issues are very much influenced by other issues and in the digraph, they are at the first or in the top position. In Fig. 3 (a) and 4(a) for OEM 1 and OEM 2, operational issue (I2) and Market of the remanufactured product (I3) are the dependent issue. In Fig. 3(b), for OEM 1, reassembly (IO3), reconditioning (IO4) and production planning and control (IO6). Whereas, in Fig. 4(b), for OEM 2, inventory (IO5), reassembly (IO3) and production planning and control (IO6) are the dependent issues. In case of Fig. 3 (c), for OEM 1, the dependent issues related to product design are avoid complexity (I3) and modular design (I2) and in Fig. 4(c), for OEM 2, design for cleaning (ID5) and design for inspection (ID6) are the dependent issue. These dependent issues show the desired purpose for successfully managing the extension of useful life through product recovery operations.

\section{Linkage issue-}

In the Linkage group, issues have strong driving and dependence power. They are very unstable in nature and require a special attention from the decision makers. Any changes in these issues will affect in decision-making process. In Fig. 3(c), for OEM 1, design for cleaning (ID5) and design for inspection (ID6) are in the third quadrant i.e. in the linkage

Table 11 Level Partitioning among the issues related to the Market of remanufactured product for OEM 1 and OEM 2

\begin{tabular}{lllll}
\hline Marketing issues (OEM 1 \& OEM2) & Reachability set & Antecedent Set & Intersection Set & Level \\
\hline Irm1 & 1 & $1,2,3$ & 1 & $\mathbf{1}$ \\
Irm2 & 1,2 & 2 & 2 & $\mathbf{2}$ \\
Irm3 & 1,3 & 3 & 3 & $\mathbf{2}$ \\
\hline
\end{tabular}


group. In Fig. 4, for OEM 2, the linkage issue is avoid complexity (ID4). These factors act as a catalyst in this model which facilitate the outcomes of the system.

\section{Independent issue-}

The independent issues have strong driving power and dependence power. These issues are very important and top management deploys more resources on these issues. In Fig. 3 (a), product design (I1), Governmental Laws \& Legislations (I4) and environmental consciousness (I5) are the driving issues for OEM 1. However, in Fig. 4 (a), for OEM 2, Governmental Laws and Legislation (I4) is the only independent issues. For Fig. 3 (b), collection process (IO1) and disassembly (IO2) are the independent issue. Whereas, disassembly is the only independent or driving issue in Fig. 4 (b). In case of issue related to product design for OEM 1, design of the fasteners, avoid complexity and minimize no. of parts are the independent issues, shown in Fig. 3 (c) and for OEM 2, design of fasteners (ID1), modular design (ID2) are the independent issues.

From Fig. 7, at level 1 there are operational and marketing issues. At level 2 there are design of the product and government legislation issues. At level 3 there is environment consciousness, which acts as a prime enabler or prime mover for the extension of useful life of a product. If we want to know the degree of impact of this issue at level 3 on other issues at level 2 and 1, we get the result from Table 3. I5 has a high impact on Market of the remanufactured product (I3), very high impact on Design of the product (I1) and Government legislation (I4), but has low impact on Operational issues (I2). Also from Figs. 7 and 8, we get some difference in the overall FISM model. In case of OEM 1, environmental consciousness is the major driving issue for practising the extension of useful life operation of the product which influences in product design and Governmental laws and legislations. Due to the environmental consciousness, OEM give more weightage on development and designing of more environmental friendly product. Also, environmental consciousness motivates the Government to set up some stringent laws and legislations. The Governmental legislations also influences to create a new market for the remanufactured product and product design influences the operational level issues. For OEM 1, product design issue is in the linkage quadrant. Thus, product design has a significant contribution in decision making related to useful life extension. OEM 1 tries to develop the new toner cartridge in such a way that it can facilitate the product recovery options specially remanufacturing. On that basis, OEM 1 gives more weightages on avoid product complexity

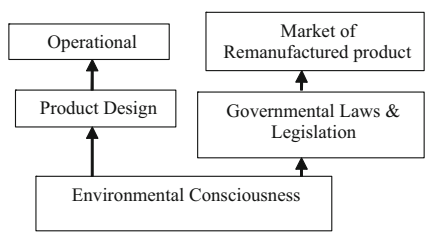

(a) FISM based model related to five main issues

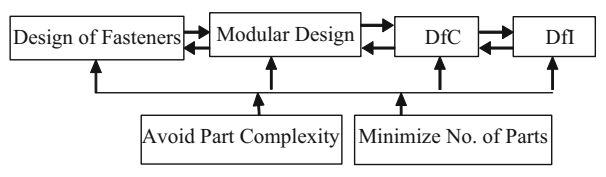

(c) FISM based model related to Design of a product

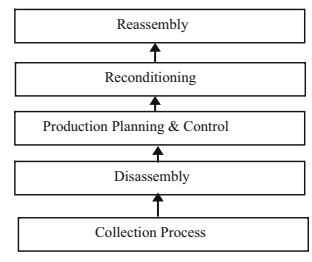

(b) FISM based model related to Operational issue

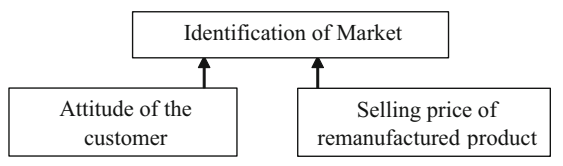

(d) FISM based model related to Market of the remanufactured product

Fig. 5 FISM model among the main issues, operational issue, design and marketing related issue for OEM 1 


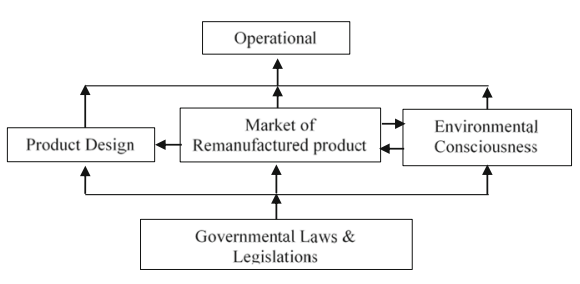

(a) FISM based model related to five main issues

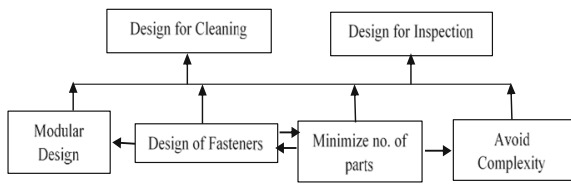

(c) FISM based model related to Design of a product

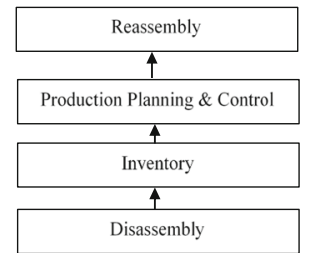

(b) FISM based model related to Operational issue

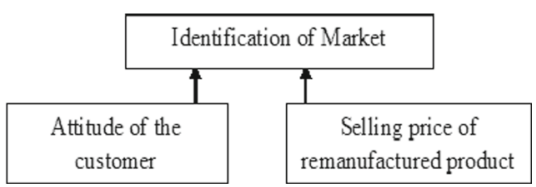

(d) FISM based model related to Market of the remanufactured product

Fig. 6 FISM model among the main issues, operational issue, design and marketing related issue for OEM 2

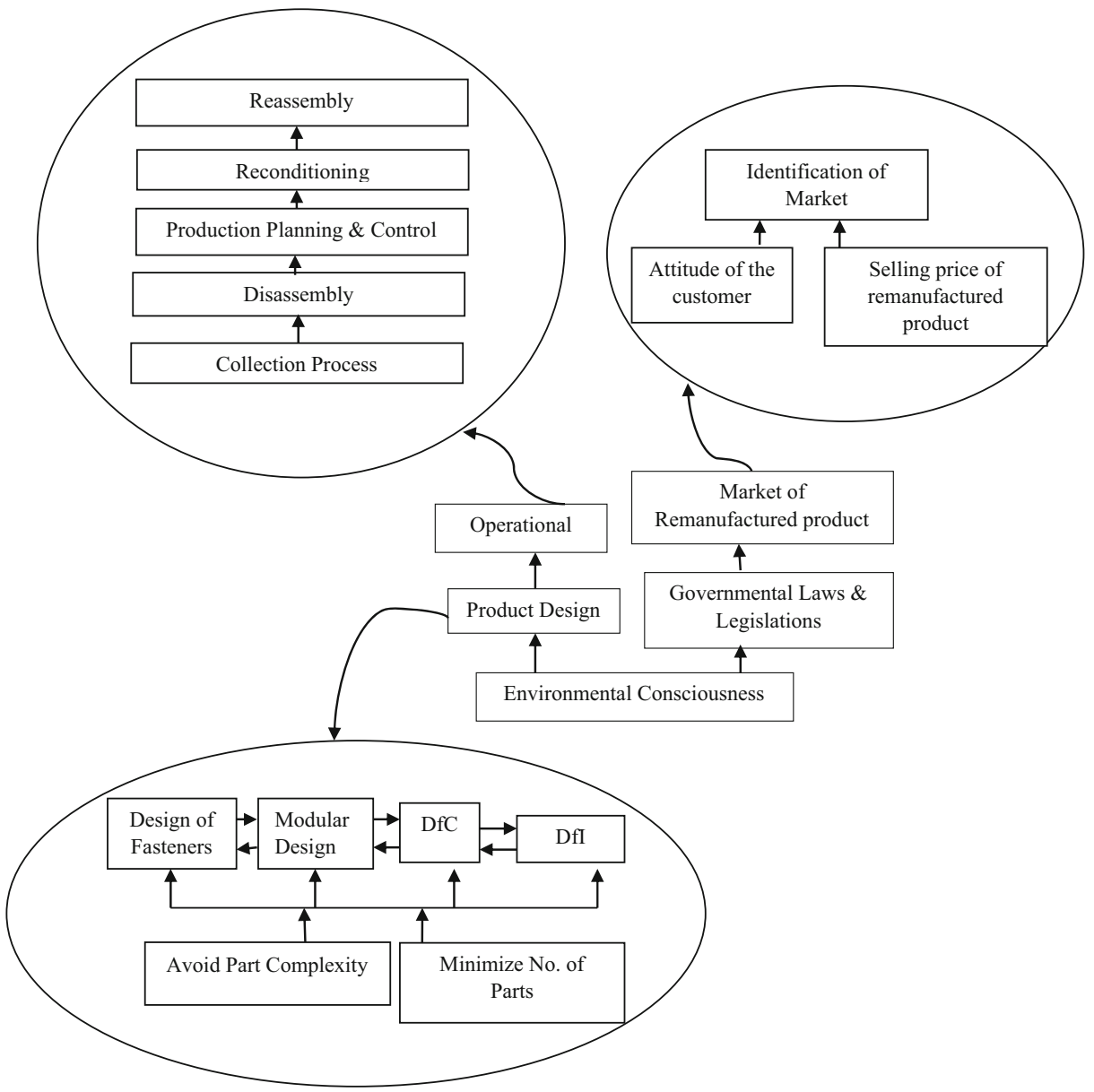

Fig. 7 Comprehensive FISM Model related to the extension of useful life of a product for OEM 1 


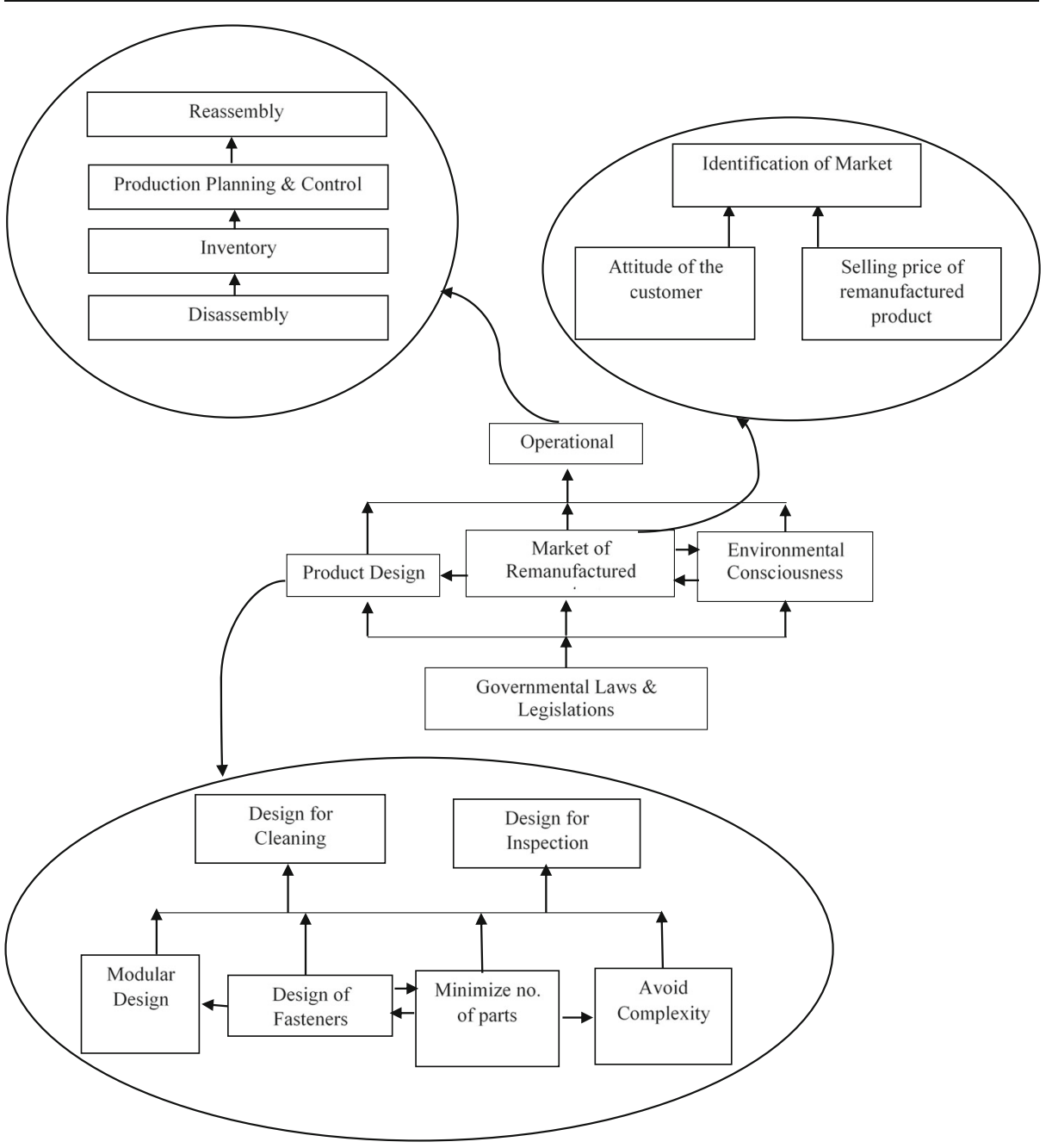

Fig. 8 Comprehensive FISM Model related to the extension of useful life of a product for OEM 2

and minimization of number of parts. Under the operational issue, OEM 1 gives more focus on the collection of the used toner cartridge. Due to huge number of customers and OEM 1 fails to maintain the proper database of their customers, they consider collection of the used cartridge is the driving issue. For the marketing related issue, OEM 1 focus on customer attitude and selling price of the remanufactured product. These two factors influence the marketing of the remanufactured product.

In case of OEM 2, they consider that Government Laws and Legislations is the important factors of the product recovery operations (shown in Fig. 8). Stringent Governmental Laws and Legislations influences in product design, remanufactured product market and environmental consciousness. For product design, OEM 2 focus on modular design, design of the fasteners, complexity and number of parts because alternator is a complex product than printer cartridge. Thus, OEM 2 give more weightage on modular design and fasteners design rather than OEM 1. For operational issue, they focus on disassembly of the used alternators because 
they have very limited customers and customers returned their product when remanufacturing is necessary.

\section{Conclusions}

The shrinking window of natural resources and global environmental consciousness are essentially compelling various industrial houses to opt for alternative technologies, which possibly help extend the useful life of a product. Product recovery operations have already been accepted globally as one of the most appropriate proposition in this pursuit. The contribution of this paper lies on identification of various issues relating to product recovery management and developing their relationships influencing the relevant business processes. Fuzzy Interpretive Structural Modelling (FISM) is proposed to establish the structural relations, which will capture the inherent ambiguity of expert-driven input data. This research project is expected to be extended in future by applying Structural Equation Modelling (SEM).

Acknowledgements Authors acknowledge the direct and indirect help and co-operations from IIT(ISM) Dhanbad and IIM Kashipur for successful completion of this research.

\section{Appendix A}

Table 12 SSIM Matrix from Experts' Opinion related to five main issues for OEM 1

\begin{tabular}{|c|c|c|c|c|c|c|}
\hline & Issues & I1 & I2 & I3 & I4 & I5 \\
\hline Expert 1 & $\begin{array}{l}\text { Product Design (I1) } \\
\text { Operational (I2) } \\
\text { Market of remanufactured product (I3) } \\
\text { Governmental Laws \& Legislation (I4) } \\
\text { Environmental Consciousness (I5) }\end{array}$ & & $\mathrm{V}(\mathrm{VH})$ & $\begin{array}{l}\mathrm{V}(\mathrm{VH}) \\
\mathrm{O}(\mathrm{No})\end{array}$ & $\begin{array}{l}A(L) \\
A(H) \\
A(H)\end{array}$ & $\begin{array}{l}\text { A }(\mathrm{VH}) \\
\mathrm{A}(\mathrm{L}) \\
\mathrm{X}(\mathrm{L}, \mathrm{H}) \\
\mathrm{A}(\mathrm{H})\end{array}$ \\
\hline Expert 2 & $\begin{array}{l}\text { Product Design (I1) } \\
\text { Operational (I2) } \\
\text { Market of remanufactured product (I3) } \\
\text { Governmental Laws \& Legislation (I4) } \\
\text { Environmental Consciousness (I5) }\end{array}$ & & $\mathrm{V}(\mathrm{H})$ & $\begin{array}{l}\mathrm{V}(\mathrm{H}) \\
\mathrm{O}(\mathrm{No})\end{array}$ & $\begin{array}{l}A(L) \\
A(L) \\
A(H)\end{array}$ & $\begin{array}{l}\mathrm{A}(\mathrm{H}) \\
\mathrm{A}(\mathrm{VL}) \\
\mathrm{X}(\mathrm{L}, \mathrm{VH}) \\
\mathrm{A}(\mathrm{VH})\end{array}$ \\
\hline Expert 3 & $\begin{array}{l}\text { Product Design (I1) } \\
\text { Operational (I2) } \\
\text { Market of remanufactured product (I3) } \\
\text { Governmental Laws \& Legislation (I4) } \\
\text { Environmental Consciousness (I5) }\end{array}$ & & $\mathrm{V}(\mathrm{H})$ & $\begin{array}{l}\mathrm{V}(\mathrm{H}) \\
\mathrm{O}(\mathrm{No})\end{array}$ & $\begin{array}{l}\mathrm{A}(\mathrm{VL}) \\
\mathrm{A}(\mathrm{L}) \\
\mathrm{A}(\mathrm{H})\end{array}$ & $\begin{array}{l}\mathrm{A}(\mathrm{H}) \\
\mathrm{A}(\mathrm{VL}) \\
\mathrm{X}(\mathrm{L}, \mathrm{H}) \\
\mathrm{A}(\mathrm{VH})\end{array}$ \\
\hline Expert 4 & $\begin{array}{l}\text { Product Design (I1) } \\
\text { Operational (I2) } \\
\text { Market of remanufactured product (I3) } \\
\text { Governmental Laws \& Legislation (I4) } \\
\text { Environmental Consciousness (I5) }\end{array}$ & & $\mathrm{V}(\mathrm{VH})$ & $\begin{array}{l}\mathrm{V}(\mathrm{H}) \\
\mathrm{O}(\mathrm{No})\end{array}$ & $\begin{array}{l}\mathrm{A}(\mathrm{VL}) \\
\mathrm{A}(\mathrm{H}) \\
\mathrm{A}(\mathrm{L})\end{array}$ & $\begin{array}{l}\mathrm{A}(\mathrm{VH}) \\
\mathrm{A}(\mathrm{L}) \\
\mathrm{X}(\mathrm{L}, \mathrm{H}) \\
\mathrm{A}(\mathrm{VH})\end{array}$ \\
\hline Expert 5 & $\begin{array}{l}\text { Product Design (I1) } \\
\text { Operational (I2) } \\
\text { Market of remanufactured product (I3) } \\
\text { Governmental Laws \& Legislation (I4) } \\
\text { Environmental Consciousness (I5) }\end{array}$ & & $\mathrm{V}(\mathrm{VH})$ & $\begin{array}{l}\mathrm{V}(\mathrm{VH}) \\
\mathrm{O}(\mathrm{No})\end{array}$ & $\begin{array}{l}A(L) \\
A(H) \\
A(L)\end{array}$ & $\begin{array}{l}\text { A }(\mathrm{VH}) \\
\text { A(L) } \\
X(L, H) \\
\text { A(H) }\end{array}$ \\
\hline
\end{tabular}




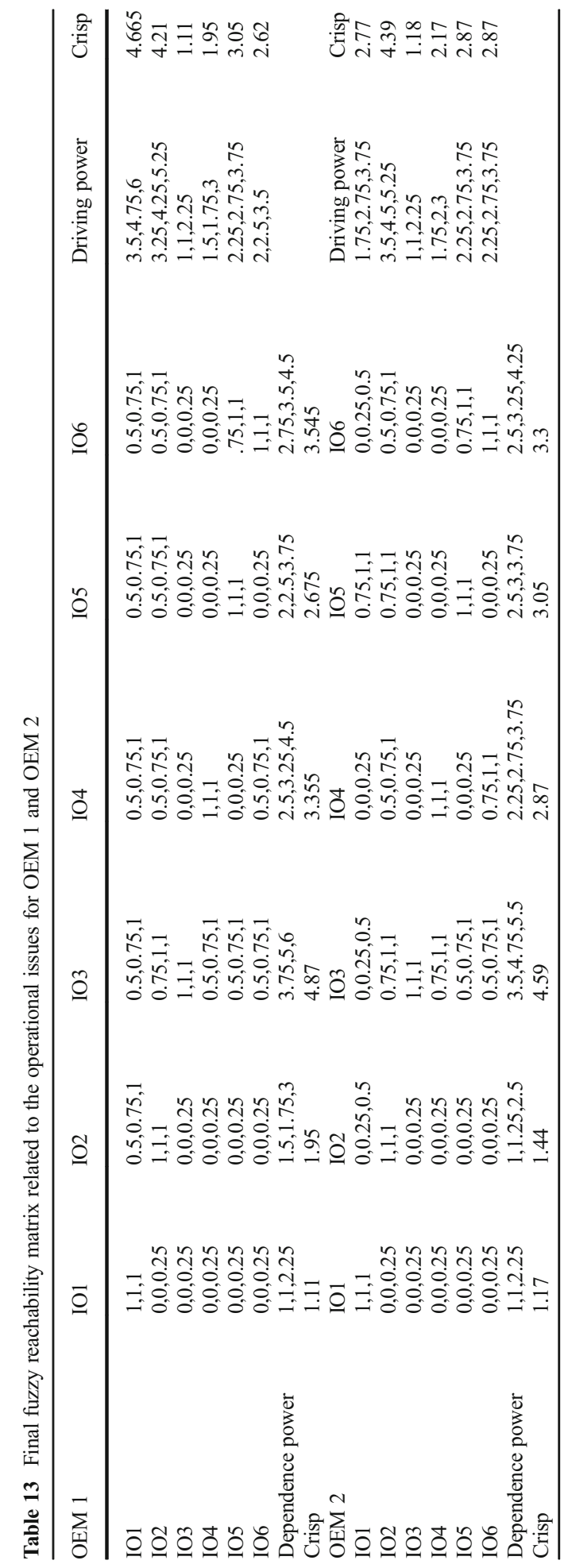




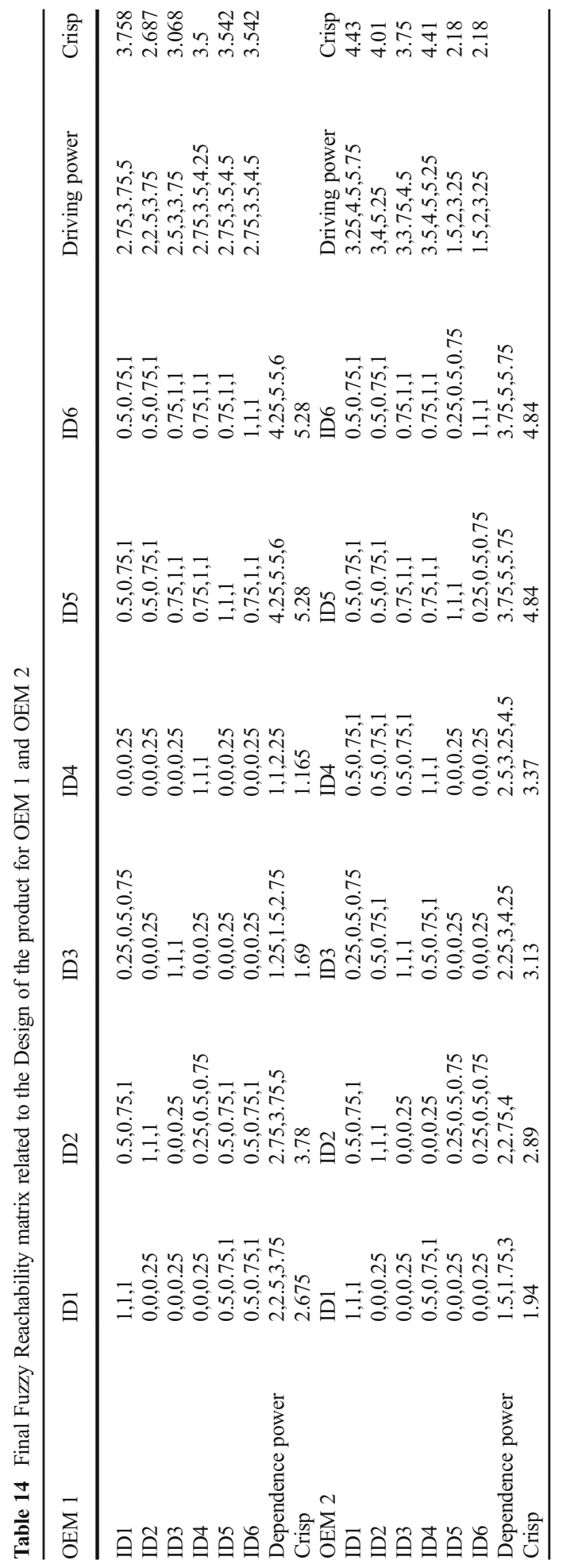


Table 15 Final Fuzzy Reachability matrix related to the Design of the product for OEM 1 and OEM 2

\begin{tabular}{llllll}
\hline OEM 1 \& OEM 2 & Irm1 & Irm2 & Irm3 & Driving power & Crisp value \\
\hline Irm1 & $1,1,1$ & $0,0,0.25$ & $0,0,0.25$ & $1,1,1.5$ & 1.07 \\
Irm2 & $0.75,1,1$ & $1,1,1$ & $0,0,0.25$ & $1.75,2,2.75$ & 1.994 \\
Irm3 & $0.75,1,1$ & $0.25,0.5,0.75$ & $1,1,1$ & $2,2.5,2.75$ & 2.428 \\
Dependence power & $2.5,3,3$ & $1.25,1.5,2$ & $1,1,1.5$ & & \\
Crisp value & 2.932 & 1.504 & 1.066 & & \\
\hline
\end{tabular}

\section{References}

1. Kobayashi H (2005) Strategic evolution of eco-products: a product life cycle planning methodology. Res Eng Des 16(1-2):1-16

2. Mondal S, Mukherjee K (2006) Buy-back policy decision in managing reverse logistics. Int J Logistics Systems and Management 2(3):255-264

3. Galberth B (2006) Optimal acquisition and sorting policies for remanufacturing. Prod Oper Manag 15(3): 384-392

4. Teunter HR, Flapper PDS (2010) Optimal Core acquisition and remanufacturing policies under uncertain core quality fractions. European Journal of Operation Research:241-248

5. Wassenhove LKV, Zikopoulos C (2010) On the effect of quality overestimation in remanufacturing. Int J Prod Res 48(18):5263-5280

6. Guide VDR, Teunter HR, Van Wassenhove LN (2003) Matching demand and supply to maximize profits from remanufacturing. Manufacturing \& Service Operations Management 5(4):303-316

7. Ferguson M, Guide VDJ, Koca E, Souza GC (2009) The value of quality grading in remanufacturing. Prod Oper Manag 18(3):300-314

8. Fleischmann M, Bloemhof-Ruwaard MJ, Dekker R, Van der Laan E, Van Nunen JAEE, Van Wassenhove LN (1997) Quantitative models for reverse logistics: a review. Eur J Oper Res 103:1-17

9. El Saadany AMA, Jaber MY (2011) A production/remanufacture model with returns subassemblies managed differently. Int J Prod Econ 133:119-126

10. Fleischmann M, Krikke HR, Dekker R, Flapper SDP (2000) A characterisation of logistics networks for product recovery. Omega 28(6):653-666

11. Shu F (1999) Application of a design-for-remanufacture framework to the selection of product life-cycle fastening and joining methods. Robot Comput Integr Manuf 15(3):179-190

12. Ijomah LW, McMohan CA, Hammond GP, Newman ST (2007) Development of design for remanufacturing guidelines to support sustainable manufacturing. Robot Comput Integr Manuf 23(6):712-719

13. Go TF, Wahab DA, Rahman MNAb, Ramli R, Azhari CH (2011) Disassemblability of end-of-life vehicle: a critical review of evaluation methods. J Clean Prod 19(13):1536-1546

14. Zwolinski P, Lopez-Ontiveros M, Brissaud D (2006) Integrated design of remanufacturable products based on product profiles. J Clean Prod 14(15-16):1333-1345

15. Kimura F, Kato S, Hata T (2001) Product modularization for parts reuse in inverse manufacturing. Annuals of CIRP 50(1):89-92

16. Brennan L, Gupta SM, Taleb KN (1994) Operations planning issues in an assembly/disassembly environment. Int J Oper Prod Manag 14(9):57-67

17. Desai A, Mital A (2003) Evaluation of disassemblability to enable design for disassembly in mass production. Int J Ind Ergon 32:265-281

18. Subramanian R, Subramanyam R (2012) Key factors in the market for remanufactured products. Manufacturing \& Service Operations Management 14(2):315-326

19. Atasu A, Guide VDR, Wassenhove LK (2008) Product reuse economics in closed-loop supply chain research. Int J Prod Econ 133:262-271

20. Parra BJ, Rubio S, Vicente-Molina MA (2014) Key drivers in the behaviour of potential consumers of remanufactured products: a study on laptops in Spain. J Clean Prod 85:488-496

21. Ostilin J, Sundin E, Bjorkman M (2009) Product life-cycle implications for remanufacturing strategies. J Clean Prod 17:999-1009

22. Rathore P, Kota S, Chakrabarti A (2011) Sustainability through remanufacturing in India: a case study on mobile handsets. J Clean Prod 19:1709-1722

23. Johnson MR, McCarthy IP (2014) Product recovery decisions within the context of extended producer responsibility. J Eng Technol Manag 34:9-28 
24. Xiang W, Ming C (2011) Implementing extended producer responsibility: vehicle remanufacturing in China. J Clean Prod 19:680-686

25. Gungor A, Gupta SM (1999) Issues in environmentally conscious manufacturing and product recovery: a survey. Comput Ind Eng 36:811-853

26. Ilgin MA, Gupta SM (2010) Environmentally conscious manufacturing and product recovery (ECMPRO): a review of the state of the art. J Environ Eng 91:563-591

27. Khatwani G, Singh SP, Trivedi A, Chauhan A (2015) Fuzzy-TISM: a fuzzy extension of TISM for group decision making. Glob J Flex Syst Manag 16(1):97-112

28. Warfield J (1973) On arranging elements of a hierarchy in graphic form. IEEE Trans: Syst, Man Cybern 2: 121-132

29. Mukherjee K, Mondal S (2009) Analysis of issues relating to remanufacturing technology - a case of an Indian company. Tech Anal Strat Manag 21(5):639-652

30. Ravi V, Shankar R (2005) Analysis of interactions among the barriers of reverse logistics. Tech Forecasting Soc Chang 72:1011-1029

31. Vivek SD, Banwet DK, Shankar R (2008) Analysis of interactions among core, transaction and relationshipspecific investments: the case of offshoring. J Oper Manag 26:180-197 